\title{
Bone metabolism changes in patients with inflammatory bowel disease
}

\author{
J. Legido, J. P. Gisbert, J. M. Pajares and J. Maté \\ Service of Digestive Diseases. Hospital Universitario de La Princesa. Madrid, Spain
}

Legido J, Gisbert JP, Pajares JM, Maté J. Bone metabolism changes in patients with inflammatory bowel disease. Rev Esp Enferm Dig 2005; 97: 815-829.

\begin{abstract}
ABBREVIATIONS
Inflammatory bowel disease (IBD), Crohn's disease (CD), ulcerative colitis (UC), bone densitometry (DXA), bone mineral density (BMD), parathormone $(\mathrm{PTH})$, gonadotropic hormone (GH), interleukin (IL), tumor necrosis factor (TNF), insulin-like growth factor (IGF), tumor growth factor (TGF), body mass index (BMI), N-telopeptides of type- 1 collagen (Ntx).
\end{abstract}

\section{INTRODUCTION}

Bone metabolism changes in patients with inflammatory bowel disease (IBD) awoke a growing interest in the past few years mostly because of their high prevalence, with estimations around 40-50\% for osteopenia and 5$30 \%$ regarding osteoporosis (1-3).

The presence of bone metabolism changes in these patients is an issue of great clinical relevance given an increased risk for bone fracture, primarily in the dorso-lumbar spine $(4,5)$.

Aims of this review include: a) an evaluation of the

Recibido: 28-08-04

Aceptado: 03-03-05.

Correspondencia: Jesús Legido Gil. Servicio de Aparato Digestivo. Hospital Universitario de La Princesa. Diego de León, 62, 3ª planta. $28006 \mathrm{Ma}-$ drid. Fax: 914022 299. e-mail: chuslegi@ hotmail.com significance of bone metabolism changes in the setting of extradigestive manifestations in ulcerative colitis (UC) and Crohn's disease (CD); b) an analysis of the various risk factors present in these patients -in addition to those well known by the general population, other factors inherent to this disease, mainly derived from corticoid use and BDI-related malabsorption, should be considered; c) an assessment of the role of hip and lumbar spine densitometry (DXA), as well as of the various biochemical parameters for bone resorption and formation than have been postulated as markers for bone metabolism changes in BDI, and whose role for screening and diagnostic purposes has been deemed likely; and d) a discussion of the various prevention strategies for osteoporosis and osteopenia, as well as of therapeutic options according to clinical findings, in order to provide a better multidisciplinary, integral management for IBD.

\section{PREVALENCE OF BONE METABOLISM CHANGES IN IBD}

Bone metabolism changes may be divided in osteopenia and osteoporosis depending upon the severity of bone mineral density (BMD) loss as seen during DXA. BMD is expressed in $\mathrm{g} / \mathrm{cm}^{2}$, and its interpretation relies on both $\mathrm{T}$ and $\mathrm{Z}$ scores. The $\mathrm{Z}$-score compares the patient to an age-, gender-, and weight-adjusted population, whereas the T-score compares the patient with same-gender individuals in their peak of bone mass (around 30 years of age). According to $\mathrm{WHO}$, osteoporosis is present when T-scores are more than 2.5 standard deviations below the population's mean value, and osteopenia exists when T-scores are between 1 and 2.5 standard deviations.

According to a great majority of studies, osteopenia develops in $40-50 \%$ and osteoporosis in $2-30 \%$ of patients with IBD (1-3, 6-12). 


\section{Differences in the prevalence of osteopenia and osteoporosis between $\mathrm{CD}$ and $\mathrm{UC}$}

Despite the fact that a greater prevalence of bone metabolism changes should be expected in patients with $\mathrm{CD}$, given the small bowel involvement and a reduced absorption of calcium and vitamin $\mathrm{D}$, most recent studies find no significant differences in the prevalence of osteoporosis between patients with UC and those with $\mathrm{CD}(3,5,6,9,13)$. However, other authors report differing results. Thus, for instance, Pollak et al. (10) found a trend towards smaller BMD in CD when compared to UC that was not related to age, disease duration, body mass index or cumulative corticoid dosage, with DXAmeasured Z-scores being statistically smaller in patients with CD. Similar results were found in two other studies $(14,15)$. In turn, Ardizzone et al. (16) described 55\% of osteoporosis and $37 \%$ of osteopenia, while figures for UC were 67 and $18 \%$, with no statistically significant differences being found between both diseases. In this study bone turnover was higher in CD. Finally, Boot et al. (17) concluded that children with $C D$ had a significantly lower BMD at the lumbar spine versus children with UC.

\section{Are bone metabolism changes already present at the time of IBD diagnosis?}

The views of the various investigators on this issue are conflicting. For example, Lamb et al. (18) demonstrated a reduction of BMD in patients with IBD already at the time of diagnosis, before corticoid therapy onset. In turn, Ghosh et al. (15) described that BMD in patients newly diagnosed with $\mathrm{CD}$ was lower versus the general population, while those with recent UC had no differences. This may be attributed to younger age and higher BMD in patients with UC as included in this study. Other objections may be made against this latter work, including a small sample, a wide age range (1483 years) and the absence of information on the percentage of menopausal women. In contrast to these studies, Schoon et al. (9), in a recent case-control study, concluded that BMD in patients newly diagnosed with IBD was not significantly decreased when compared to controls. Therefore, the aforementioned studies suggest that the development of osteoporosis results from both disease-related (inflammatory activity, malabsorption, etc.) and treatment-related (corticoids) mechanisms.

\section{Is BMD reduced in pediatric patients with IBD?}

Few studies exist in this population group. One of them (17) demonstrates reduced bone mineralization, as well as decreased BMD at the lumbar spine; BMD showed a negative correlation to delayed bone maturation and puberty. In turn, Semeao et al. (19) reported on 5 children with IBD who had vertebral compression fractures; all had a BMD far below mean values in the general population.

\section{PATHOPHYSIOLOGY}

Bone is a dynamic tissue where, in a continual and coordinated manner, both osteoblastic (bone-forming) and osteoclastic (bone-resorbing) activities take place, which results in so-called bone remodeling. The final result must be balanced between both processes; thus, when resorption predominates against formation, this balance results in a loss of bone mass, as occurs in the presence of formation deficiencies.

Several factors are involved in the regulation of bone remodeling -mechanic, systemic (effects of various hormones and proteins: parathormone (PTH), tiroxine, gonadotropic hormone $(\mathrm{GH})$, estrogen, and vitamin $\mathrm{D}$, which stimulate bone formation, and calcitonin and glucocorticoids, which reduce it), and local [activity of various cytokines that stimulate resorption (interleukins (IL-1 and IL-6) or tumor necrosis factor alpha (TNF-alpha)] or bone formation [insulin-like growth factors (IGF-1 and IGF-2) or tumor growth factor beta (TGF-beta)].

In patients with IBD a close association between disease activity and bone mass reduction has been noted, mediated by the release of selected cytokines. Thus, TNF-alpha and IL-6 levels increase in CD, which stimulate osteoclast activity to result in bone remodeling impairment, with a predominance of resorption. In contrast, cytokines predominating in UC include IL-4 and IL-10, while their effects on bone remodeling are unknown (20).

Whether it is reduced bone formation or increased bone resorption that influences most decreased bone mineral density is a controversial issue. In a recent Dutch report a reduction in bone formation and normal resorption levels were noted in patients with long-standing CD (21). In contrast, according to other studies $(11,18,22,23)$ reduced BMD primarily results from increased bone resorption.

\section{ETIOPATHOGENESIS AND RISK FACTORS}

1. Use of glucocorticoids: the use of corticoids in IBD is doubtless a most determinant factor in the development of bone metabolism changes in these patients. During the first year of therapy severe bone loss occurs, which subsequently lingers to a lesser extent $(9,24)$. Corticoids exert a direct inhibitory effect on osteoblasts, thus altering their role in gene transcription. Similarly, the amount of calcium absorbed decreases, and urinary calcium increases. The result is a decrease in total body calcium that stimulates a secondary increase of PTH, which in turn 
stimulates osteoclast activity. Corticoids have a direct suppressor effect on pituitary function, inducing a decrease in testosterone and estrogen production (25).

A British study (26) demonstrated a higher prevalence of osteoporosis in patients with IBD who were on oral steroids versus those who were not. Similarly, the cumulative dose of corticoids significantly correlated with BMD at the lumbar spine and femoral neck. In addition, mean daily dose was greater in patients with osteoporosis and osteopenia. A German study performed in 25 patients with CD flare-ups demonstrated a reduction in BMD at 3 months after treatment onset, which emphasizes the short-term effect of corticoids on bone metabolism (27). However, Habtezion et al. (28) found that cumulative dose was not a good predictor of bone loss, as the latter was not effected by steroid doses used for flare-ups. A Dutch study demonstrated a higher use of corticoids in patients with osteoporosis, with a negative correlation between cumulative steroid dose and DXA-measured Z-score at the lumbar spine, and also established total cumulative steroid dose as an independent variable (29). In another interesting research from this same country patients were divided up into three groups: those who had never taken corticoids, those who had received corticoids before the analysis, and those who were corticoid-dependent; the lowest BMD scores were found in the latter. Almost two thirds of the patients who had never been on corticoids had a normal $\mathrm{BMD}$, whereas this was the case for fewer than a half of corticoid-dependent subjects (2). A reduced BMD in association with cumulative steroid dose was also demonstrated, which is in contrast with the findings by other authors (10). A study of pediatric patients found a significant negative correlation between steroid therapy and both total and lumbar spine BMD (17). In contrast with these investigations, Bjarnason et al. (11) found no relationship between $\mathrm{BMD}$ and current or prior corticoid use.

In summary, it may be stated that corticoid use is a major risk factor for the development of osteoporosis, with bone mass loss being more relevant during the first months of therapy. This negative effect correlates in most studies with total cumulative dose.

2. Sex: no statistically significant differences in BMD have been found in most studies between males and females $(3,10,12,28)$; however, some reports $(2,26)$ do demonstrate a higher prevalence of osteoporosis among males (in patients with $\mathrm{CD}$ ), and this variable has been ultimately considered an independent risk factor.

3. Disease duration: de Jong et al. (29) found a statistically significant association between prevalence of osteoporosis and duration of CD. In turn, Habtezion et al. (28) demonstrated a lower BMD in patients with longer disease, but this difference was not significant when age was adjusted for. Similarly, Pollak et al. (10) found no differences in the duration of disease between patients with and without osteoporosis. Finally, no relationship was noted between disease duration and both total and lumbar spine BMD in a study of pediatric patients (17).
4. Disease activity: most studies have found no association between disease activity and presence of osteoporosis $(2,11,26,28)$. This may result from the fact that disease activity assessment occurs at a given point in time rather than along a prolonged period, which would likely demonstrate an association of inflammatory activity with reduced BMD, the development of which takes months or even years. Nevertheless, some patients with IBD already exhibit a reduced BMD at diagnosis, even before any therapies are received (6), and it has been speculated that a number of cytokines involved in acute inflammation may mediate bone metabolism changes.

5. Disease localization: although patients with small bowel involvement (in CD) should theoretically have decreased calcium and vitamin D absorption, and thus increased osteopenia, most reports have demonstrated no association between prevalence of osteoporosis and disease localization $(11,28,29)$. Exceptionally, some authors have described a decreased BMD at the lumbar spine and femoral neck in patients with jejunal involvement (26).

6. Prior resection surgery: according to most studies, an association between the prevalence of bone metabolism changes and prior intestinal resection is seemingly the case in patients with CD and UC. A research by De Jong et al. (29) noted a statistically significant correlation between osteoporosis and a history of intestinal resection, as well as with the length of the resected segment. Pollak et al. (10) found a lower bone mineral density in patients with ileostomy both in the lumbar spine and femoral neck as measured by DXA. Similarly, another study found that BMD as measured by DXA was significantly lower at the hip of patients with prior ileostomy (26). However, as usual, conflicting studies have found no association between BMD and prior resection among adults (2) and children (17) with IBD.

7. Vitamin D and calcium deficiency: vitamin D deficiency is common in patients with IBD, and has been described in up to $65 \%$ of cases based on a number of studies (6). This problem partly results from a low intake of dietary milk and dairy products. Thus, Silvennoinen et al. (7) found that calcium intakes inferior to $1 \mathrm{~g}$ daily were more common in patients with CD versus healthy subjects. However, other authors could not demonstrate this correlation (28). Pollak et al. (10) found no association between vitamin $\mathrm{D}$ levels and the presence or absence of osteoporosis in these patients. However, in a study of pediatric patients vitamin D deficiency was noted in $10 \%$ of subjects, which may suggest an etiopathogenic role in bone loss (17). An additive factor is malabsorption and intestinal resection, a common occurrence in this group of patients.

8. Physical activity: most studies of patients with IBD have demonstrated no association between physical activity and presence of osteoporosis with reduced BMD both in adults $(26,28)$ and children (17).

9. Genetic factors: the balance between pro-inflammatory and anti-inflammatory cytokines influences chronic inflammation and bone resorption mechanisms $(24,30,31)$. 
IL-6 and IL-1 play a nuclear role in the paracrine stimulation of osteoclasts and the regulation of resorption. A German study has shown that some genetic variations in the genes coding for IL- 6 and IL-1 identify patients with a risk for increased bone loss (30).

10. Body mass index (BMI): as is well known, body mass index is defined as the ratio between body weight (in kilograms) and squared height (in meters). De Jong et al. (29) demonstrated a significantly lower level of BMI in patients with $\mathrm{CD}$ and osteoporosis versus patients with none of these disturbances in bone metabolism. A study of children with IBD found a lower BMI as compared to the healthy children population (17); in addition, low IGF-I (insulin-like growth factor I) levels were found in $22 \%$ of subjects. This BMI reduction may be due to malnutrition as a consequence of malabsorption or to higher disease activity. Furthermore, a number of studies found a positive correlation between bone mineral density (BMD) and body mass index (BMI), in such a way that low values for the latter is one of the best predictors for bone loss $(26,28,32)$.

11. Sexual hormones: a disturbance of sexual hormone function occurs in IBD from the inhibitory effects of disease itself on pituitary function and glucocorticoid use, with amenorrhea and hypogonadism being common in these patients (6). Robinson et al. (33) measured total serum testosterone, gonadotropins, and a number of bone remodeling markers in a study, and found a statistically significant association between total testosterone and osteocalcin that could not be accounted for by age or steroid use.

12. Vitamin $K$ : a Dutch study showed significantly lower vitamin $\mathrm{K}$ levels in patients with $\mathrm{CD}$ versus healthy controls (34). This vitamin is a cofactor in the carboxylation of osteocalcin, an essential protein for the binding of calcium to bone. Given this, high levels of circulating free or decarboxylated osteocalcin represent a sensitive marker for vitamin $\mathrm{K}$ deficiency.

13. Smoking and drinking: most studies in subjects with IBD show no difference in the prevalence of osteoporosis between smokers and non-smokers $(2,26,28,29)$. In contrast, Silveinnoinen et al. (23) documented a lower age-adjusted bone mineral density in smoking or exsmoking women versus non-smoking females, but no differences were found for males. Regarding drinking, Robinson et al. (26) found no association between bone mineral density and alcohol use.

\section{CLINICAL RELEVANCE OF BONE METABOLISM CHANGES IN IBD}

Bone metabolism changes (osteoporosis and osteopenia) are associated with a high risk of fracture at the spine, hip, and radius, resulting in significant morbidity and mortality. These fractures clinically manifest with chronic back pain, height loss, spinal deformity, and disability. Most publications have documented an increased prevalence of fractures in patients with $\mathrm{CD}$ and $\mathrm{UC}$, with an increased relative risk versus the healthy population around $1.5(4,5,35)$.

The first of these works (4), performed in patients with $\mathrm{CD}$, documented that lumbar spine BMD was significantly reduced in patients with fractures, while this was not the case with hip BMD. The prevalence of osteoporotic vertebral fractures was $22 \%$, this being higher in patients with osteoporosis than in patients with osteopenia. Similarly, the presence of a fracture increased the risk for subsequent vertebral fractures 10 fold. A low clinical relevance for fractures was also documented, and these were silent in 30 of 34 patients with such lesions.

In accordance to what has been previously discussed, Arden et al. (36) demonstrated an incidence of fracture that was $40 \%$ greater than that of the general population (12), with a significant increase of fractures at the lumbar spine, hip, wrist, and rib. Similar results were obtained from another recently published study, with a risk for hip fracture in these patients of $60 \%$ (37).

In a multicenter study reported by Stockbrügger et al. (2) three groups were established: corticoid-dependent patients, corticoid-naive subjects, and patients presently not on corticoids who had used them earlier in their lives. The overall prevalence of vertebral fractures found was $14 \%$, with no statistically significant differences between groups. All fractures documented by using imaging techniques remained asymptomatic. In this respect, Jahnsen et al. (14) found fractures in $27 \%$ of 60 patients with $\mathrm{CD}$.

Finally, in a series of 5 children with $C D$ and vertebral fractures a significant reduction of BMD was seen in all cases. Common characteristics included female gender, severe disease with ileal and ascending colic involvement, high rate of hospital admissions, and high exposure to glucocorticoids (19).

In contrast with previous investigations, Loftus et al. (38) found no increased risk for fractures in patients with $\mathrm{CD}$ versus the healthy population. A cohort study documented a cumulative incidence of 36 versus $32 \%$ among controls, with a relative risk of 0.9. Age was the only clinical variable that was seen in significant association with increased fracture risk.

Managing pathologic fractures: if symptomatic (rare), we recommend relative rest, rehabilitation directed to correct abnormal postures and to increase muscular tonus, local heat, and analgesia, while non-steroidal antiinflammatory drugs should be avoided because of their deleterious effect on IBD itself.

Therefore, it may be concluded that most studies analyzed have shown an increased risk for bone fracture in patients with IBD on corticoid therapy; such fractures usually remain asymptomatic, and their prevalence correlates with BMD. 


\section{DIAGNOSIS}

A most controversial aspect of the present topic is related to diagnostic modalities as used to screen bone metabolism changes. For BMD assessment, lumbar spine and femoral neck DXA is the most commonly used firstchoice test $(10,20,39-41)$.

Most reports document a higher reduction of BMD at the femoral neck versus the lumbar spine $(10,11,29)$.

\section{Should osteoporosis screening tests be used for all patients with IBD?}

A majority of authors agree that only patients with selected risk factors for osteoporosis, among them those with prolonged corticoid use (more than 3 months per year), and older persons (mainly women older than 65 or older than 50 with a family history of osteoporosis, a personal history of fractures, low body weight, or smoking status) should be screened by DXA (41-43).

In contrast, other authors (44) advocate for generalized screening based on the high prevalence of osteoporosis and osteopenia in these patients, and the increased fracture risk this entails.

\section{Bone remodeling biochemical markers: may we use them as a screening and diagnostic modality for osteoporosis in patients with IBD?}

These markers reflect bone metabolism and correlate with the rate of bone loss. They may be divided into formation (alkaline phosphatase, osteocalcin, etc.) and resorption (urinary deoxypyridinoline, N-telopeptides of type 1 collagen, etc.). In contrast to postmenopausal osteoporosis, where both formation and resorption markers are elevated, in most studies in patients with IBD only the latter are elevated $(11,18,26,45)$.

Urinary N-telopeptides of type 1 collagen (Ntx): they are a by-product of type 1 collagen (the major component of bone matrix) degradation by osteoclasts. Research as reported by Bregenzer et al. (3) included 72 consecutive patients, and a negative correlation of BMD with Ntx was demonstrated, with no differences in Ntx levels between both sexes. Urinary Ntx levels were selected above which a negative predictive value of $100 \%$ for osteoporosis was ensured. Thus, this marker has been suggested as useful to exclude individuals not requiring densitometry. Another Israeli investigation found elevated Ntx levels in $25 \%$ of patients under study, and a negative correlation was also found between hip BMD and Ntx levels (10).

Urinary deoxypyridinoline: Lamb et al. (18) found decreased levels in patients with IBD as compared to control subjects with irritable bowel syndrome. Ledro-Cano et al. (46) established a reverse correlation between deoxypyridinoline and osteocalcin, but could document no association between bone formation/resorption biochemical markers and DXA measurements.

Alkaline phosphatase: some authors found no statistically significant differences in alkaline phosphatase levels between patients with IBD and control subjects $(10,11)$. In contrast, Schoon et al. (21) did demonstrate decreased levels of this marker in patients with longstanding CD. Furthermore, Bregenzer et al. (3) established a significant correlation between lumbar spine BMD and alkaline phosphatase levels.

Osteocalcin: some authors found no differences in osteocalcin estimates between patients with IBD and control subjects $(11,18)$. However, Schoon et al. (21) did find lower osteocalcin levels in patients with long-standing CD. Another study showed that $7 \%$ of individuals with $\mathrm{CD}$ had decreased osteocalcin; interestingly, however, these were higher in the group with osteoporosis (10) versus those with no bone metabolism changes.

Further studies are needed to eventually demonstrate the usefulness of such biochemical parameters of bone turnover as a tool for the screening and diagnosis of osteoporosis in patients with IBD.

\section{PREVENTION AND TREATMENT}

1. Physical exercise: moderate physical activity using periodically scheduled exercises may increase BMD in patients with osteopenia $(6,24)$, and is recommended for the prevention of bone metabolism changes. However, most studies in patients with IBD have shown no statistically significant association between physical activity and the prevalence of osteoporosis or decreased $\operatorname{BMD}(26,28)$.

2. Diet: adequate calcium intake is recommended for the prevention of osteoporosis in these patients, with a total allowance of $1500 \mathrm{mg} /$ day all dietary and supplemental amounts considered $(6,31,47)$.

3. Avoid excessive corticoid use: all patients requiring systemic steroids should use the lowest dose possible for the shortest period of time. Alternate day therapy, occasionally used in children, has shown no benefits in terms of BMD preservation $(24,32)$. Regarding the prevention of osteoporosis, the fact that the greatest bone loss occurs during the initial three to six months of management with corticoids should not be forgotten. A feasible option is the administration of budesonide instead of prednisolone, which is associated with decreased systemic activity. Other drug options to reduce corticoid requirements should be assessed in these patients (5-aminosalicylates, azathioprine, 6-mercaptopurine, infliximab, etc).

4. Calcium and vitamin D supplements: combined calcium and vitamin $\mathrm{D}$ has been shown to reduce bone loss rates, particularly in patients using high-dose corticoids (more than $5 \mathrm{mg} /$ day for 6 months) $(6,25,20,32)$. In a recent study (1), the administration of both supplements significantly increased BMD at the lumbar spine, as measured by DXA, in osteoporotic patients with IBD. 
Vogelsang et al. (48) demonstrated in a randomized study a significant increase of BMD in patients with CD receiving vitamin $\mathrm{D}$ therapy for 1 year when compared to the control group. The recommended dose is $400 \mathrm{IU} /$ day for vitamin D and 1000-1500 mg for calcium, while for some authors this dose may not be adequate for $\mathrm{CD}$ with small bowel involvement, because of a smaller absorption in such cases (6). Regarding formulation type, it is advisable that calcium citrate rather than calcium carbonate be administered, as the former is better absorbed (6). Regarding vitamin $\mathrm{D}$, a number of studies show a lower incidence of undesirable effects (hypercalcemia, hypercalciuria) with cholecalciferol (vitamin D3, a natural-occurring, animalorigin variation of this vitamin) versus calcitriol $(1 \alpha, 25-$ $(\mathrm{OH})_{2}$-D3, the active form of vitamin D) $(25,32)$. Regarding the timing for calcium and vitamin D supplementation, most studies recommend it for DXA t-scores below -1 DS (24).

5. Thiazide diuretics: their potential benefits are based upon the fact that they may block urinary calcium excretion, which is increased in patients on corticoids. The American College of Rheumatology recommends the inclusion of thiazide diuretic in the treatment of osteoporosis for patients with IBD (25) when 24-h urinary calcium is increased.

6. Calcitonin: the use of this hormone is based on its potential to inhibit bone resorption, and is usually associated with $500 \mathrm{mg}$ of calcium (31). Regarding routes, nasal sprays (100-200 IU/day) are unavailable in most hospitals, and calcitonin is thus usually administered by the subcutaneous or intramuscular route. More recent studies showed no significant increases in BMD, and because of this, and its high cost, its use cannot be recommended $(25,32)$.

7. Sexual hormones: several studies have shown that estrogen-based hormone replacement therapy reduces bone density loss as measured by DXA as a result of its ability to decrease bone turnover and the effects of corticoid-related hypogonadism $(6,25)$. The use of hormone replacement therapy in postmenopausal females has shown a reduction in the rate of vertebral fractures, and eight women had to be treated for 1 year in order to prevent 1 fracture (32). Witdrawal is followed by an increase in the rate of bone loss, but with a severity similar to that seen in a woman with no baseline osteoporosis. The maximum benefit occurs with long-term treatment, but this strategy is not always accepted by the patient as a result of potential shortcomings, including the return of menstruation and an increased risk for breast cancer.

Testosterone may be used in short therapy courses for males on chronic steroids, many of them with hypogonadism. Testosterone not only has been seen to prevent bone mass loss, but may also increase bone mass at the lumbar spine $(25,32)$.

8. Sodium fluoride: it increases bone-forming activity by stimulating osteoblasts. A study recently reported by Abitbol et al. (1) analyzed the effect of sodium fluoride on lumbar spine BMD in osteoporotic patients with IBD under treatment with vitamin D and calcium, and no benefits were demonstrated. In contrast, another investigation found a significant increase in lumbar spine BMD at 1 year after treatment onset with vitamin $\mathrm{D}$, calcium, and sodium fluoride versus patients on only calcium and vita$\min \mathrm{D}(49)$.

9. Bisphosphonates: bisphosphonates are synthetic analogs of inorganic pyrophosphates that inhibit bone resorption. Of all treatments discussed, bisphosphonates alone have shown efficacy in corticoid-induced osteoporosis. The ideal duration of treatment has not been established yet, but the drug should be replaced if DXAmeasured BMD keeps declining for two years. If BMD becomes stable or even improves, treatment should be maintained for three years, and possibly for as long as osteoporosis is present. If no decrease in bone mass is seen at 1 year after treatment completion, this therapy should be reinitiated (32).

Several recent studies have demonstrated that bisphosphonates are effective both in the prevention and the treatment of established osteoporosis. Adachi et al. (50) performed a trial in 141 patients who had taken corticoids (mean $20 \mathrm{mg} /$ day) for fewer than 100 days, who were randomized to receive etidronate $400 \mathrm{mg}$ or placebo. A significant increase in BMD was seen at the lumbar spine and the trocanter in patients receiving the bisphosphonate, even though the rate of new fractures was similar in both groups. Similar conclusions were arrived at in another investigation (51), and a lower incidence of fractures in postmenopausal women was seen in the group receiving alendronate. A US group (25) performed a randomized trial where a group of patients was administered risedronate. After 1 year of therapy, BMD significantly increased at the lumbar spine, femoral neck, and femoral trocanter in the group treated with risedronate versus the control group. Similar results were obtained by a British group that analyzed 74 patients and used pamidronate in a randomized clinical trial (52).

A recent revision suggests that bisphosphonates should be restricted to patients with a high risk for fracture development, once the potential for hypogonadism and the adequacy of HRT had been excluded (53). Some authors recommend the use of bisphosphonates when DXA T-scores are below -2.5 standard deviations or between -1 and -2.5 , and there is a concomitant use of steroids or the presence of additional risk factors.

They are well tolerated with scarce secondary effects, including nausea, diarrhea, or constipation. Alendronate may induce esophagitis and esophageal ulceration, and thus must be administered with $200 \mathrm{ml}$ of water.

\section{CONCLUSIONS}

Bone metabolism changes in patients with IBD have drawn increasing attention in recent years; the prevalence 


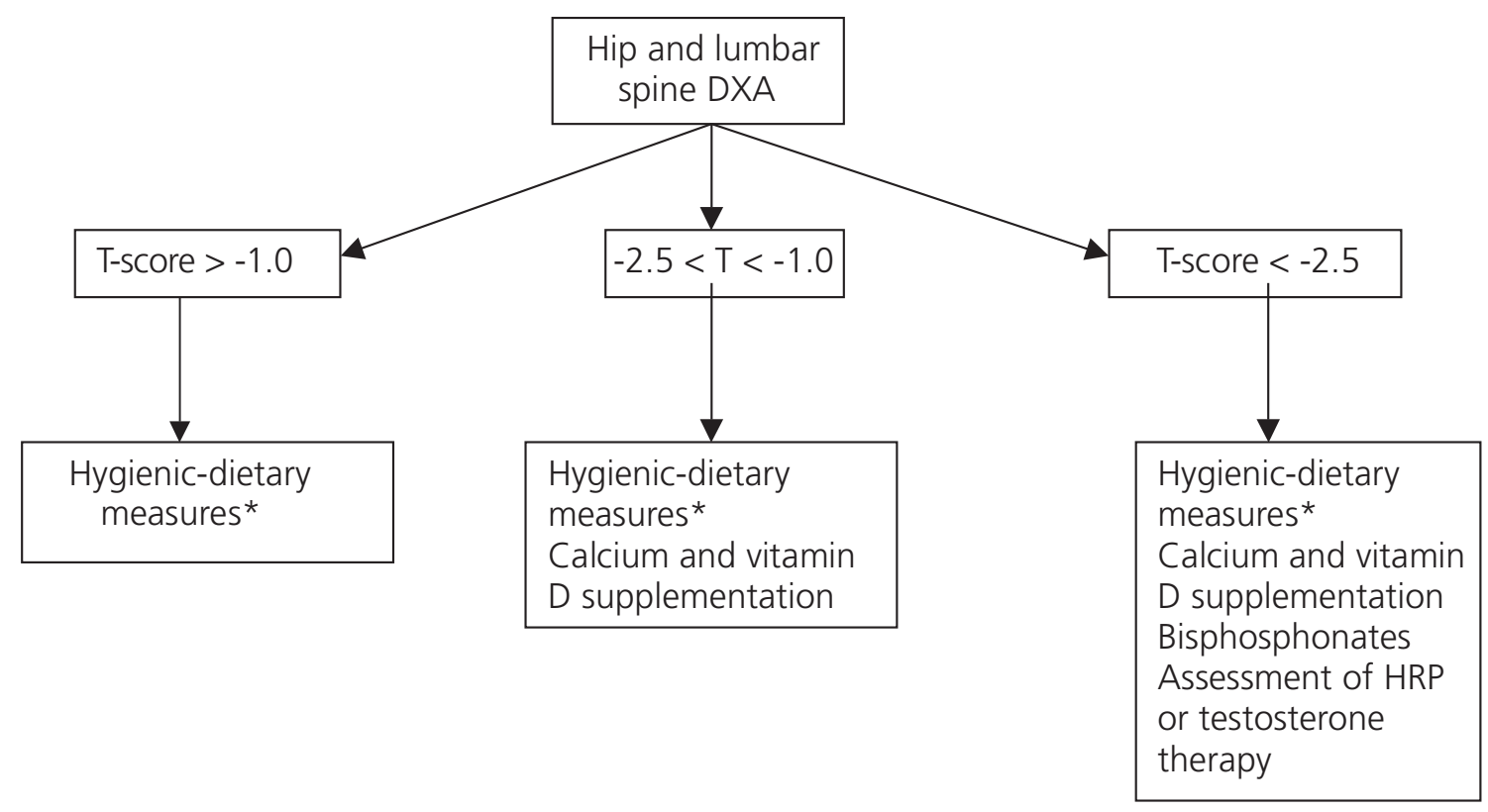

DXA: bone densitometry

HRT: hormone replacement therapy

*Exercise, adequate calcium intake, avoid alcohol and smoking

Fig. 1. Therapeutic algorithm for bone metabolism changes in patients with IBD.

Algoritmo terapéutico de las alteraciones del metabolismo óseo en los pacientes con Ell.

of osteopenia in these patients is estimated in $40-50 \%$, with this percentage oscillating between 2 and $30 \%$ in the case of osteoporosis. Most probably, these changes are already present early in the natural history of this disease, and no significant differences between UC and CD are apparent. Regarding the etiopathogenesis of osteoporosis in these patients, the use of corticoids seems to play a crucial role, with bone loss being most relevant during early therapy. Multiple risk factors for bone metabolism changes include IBD's inherent inflammatory activity, duration, and localization; previous intestinal resection surgery, and calcium and vitamin D deficiency. An increased risk for bone fracture has been demonstrated in patients with IBD receiving corticoids; these fractures are usually asymptomatic, and their prevalence correlates with BMD. DXA is the primary tool in the screening and diagnosis of osteoporosis, while the various laboratory parameters require further study to confirm their role. According to most authors, DXA screening is only recommended for patients with selected risk factors for osteoporosis, including long-term use of corticoids (more than 3 months per year), and for older individuals (mainly women older than 65 years of age or older than 50 with a family history of osteoporosis, a personal history of fractures, low body weight, or smoking status). Regarding prevention and treatment, hygienic-dietary measures such as adequate calcium intake and moderate exercise should be adopted. Depending on DXA results, we shall begin treatment with calcium and vitamin $\mathrm{D}$ supplementation, alone or in combination with bisphosphonates. Sexual hormones (testosterone, hormone replacement therapy) will be restricted to selected patients. Figure 1 summarizes a therapeutic algorithm for bone metabolism changes in patients with IBD.

\section{REFERENCES}

1. Abitbol V, Mary JY, Roux C, Soule JC, Belaiche J, Dupas JL, et al Osteoporosis in inflammatory bowel disease: effect of calcium and vitamin D with or without fluoride. Aliment Pharmacol Ther 2002; 16: $919-27$.

2. Stockbrugger RW, Schoon EJ, Bollani S, Mills PR, Israeli E, Landgraf L, et al. Discordance between the degree of osteopenia and the prevalence of spontaneous vertebral fractures in Crohn's disease. Aliment Pharmacol Ther 2002; 16: 1519-27.

3. Bregenzer N, Erban P, Albrich H, Schmitz G, Feuerbach S, Scholmerich J, et al. Screening for osteoporosis in patients with inflammatory bowel disease by using urinary N-telopeptides. Eur J Gastroenterol Hepatol 2002; 14: 599-605.

4. Klaus J, Armbrecht G, Steinkamp M, Bruckel J, Rieber A, Adler G, et al. High prevalence of osteoporotic vertebral fractures in patients with Crohn's disease. Gut 2002; 51: 654-8.

5. Bernstein CN, Blanchard JF, Leslie W, Wajda A, Yu BN. The incidence of fracture among patients with inflammatory bowel disease. A population-based cohort study. Ann Intern Med 2000; 133: 795-9. 
6. Rosen H. metabolic bone disease in inflammatory bowel disease. Up to date $2000 ; 8$.

7. Silvennoinen JA, Karttunen TJ, Niemela SE, Manelius JJ, Lehtola JK. A controlled study of bone mineral density in patients with inflammatory bowel disease. Gut 1995; 37: 71-6.

8. Compston JE. Review article: osteoporosis, corticosteroids and inflammatory bowel disease. Aliment Pharmacol Ther 1995; 9: 237-50.

9. Schoon EJ, Blok BM, Geerling BJ, Russel MG, Stockbrugger RW, Brummer RJ. Bone mineral density in patients with recently diagnosed inflammatory bowel disease. Gastroenterology 2000; 119: $1203-8$.

10. Pollak RD, Karmeli F, Eliakim R, Ackerman Z, Tabb K, Rachmilewitz D. Femoral neck osteopenia in patients with inflammatory bowel disease. Am J Gastroenterol 1998; 93: 1483-90.

11. Bjarnason I, Macpherson A, Mackintosh C, Buxton-Thomas M, Forgacs I, Moniz C. Reduced bone density in patients with inflammatory bowel disease. Gut 1997; 40: 228-33.

12. American Gastroenterological Association medical position statement: guidelines on osteoporosis in gastrointestinal diseases. Gastroenterology 2003; 124: 791-4.

13. Bernstein CN. Treatment of the extraintestinal manifestations of inflammatory bowel disease. Curr Gastroenterol Rep 2002; 4: 513-6.

14. Jahnsen J. Bone mineral density is reduced in patients with Crohn's disease but not in patients with ulcerative colitis: a population based study. Gut 1997; 40: 313-4.

15. Ghosh S. Low bone mineral density Crohn's disease, but not in ulcerative colitis at diagnosis. Gastroenterology 1994; 107: 1031-9.

16. Ardizzone S, Bollani S, Bettica P, Bevilacqua M, Molteni P, Bianchi Porro G. Altered bone metabolism in inflammatory bowel disease: there is a difference between Crohn's disease and ulcerative colitis. J Intern Med 2000; 247: 63-70.

17. Boot AM, Bouquet J, Krenning EP, de Muinck Keizer-Schrama SM. Bone mineral density and nutritional status in children with chronic inflammatory bowel disease. Gut 1998; 42: 188-94.

18. Lamb EJ, Wong T, Smith DJ, Simpson DE, Coakley AJ, Moniz C, et al. Metabolic bone disease is present at diagnosis in patients with inflammatory bowel disease. Aliment Pharmacol Ther 2002; 16: 1895902 .

19. Semeao EJ, Stallings VA, Peck SN, Piccoli DA. Vertebral compression fractures in pediatric patients with Crohn's disease. Gastroenterology 1997; 112: 1710-3.

20. García-Planella E. DE. Osteopenia y osteoporosis en la enfermedad inflamatoria intestinal. Gastroenterol Hepatol 2004; 27: 417-24.

21. Schoon EJ, Geerling BG, Van Dooren IM, Schurgers LJ, Vermeer C, Brummer RJ, et al. Abnormal bone turnover in long-standing Crohn's disease in remission. Aliment Pharmacol Ther 2001; 15: 783-92.

22. Robinson RJ, Iqbal SJ, Al-Azzawi F, Abrams K, Mayberry JF. Sex hormone status and bone metabolism in men with Crohn's disease. Aliment Pharmacol Ther 1998; 12: 21-5.

23. Silvennoinen JA, Lehtola JK, Niemela SE. Smoking is a risk factor for osteoporosis in women with inflammatory bowel disease. Scand J Gastroenterol 1996; 31: 367-71.

24. Silverberg MS. Bone density in inflammatory bowel disease. Clinical perspectives in gastroenterology, 2000.

25. Cohen S. Diagnosis and management of the bone mineral effects of inflammatory bowel disease: Crohn's and Colitis Foundation of America.

26. Robinson RJ, al-Azzawi F, Iqbal SJ, Kryswcki T, Almond L, Abrams $\mathrm{K}$, et al. Osteoporosis and determinants of bone density in patients with Crohn's disease. Dig Dis Sci 1998; 43: 2500-6.

27. von Tirpitz C. Effect of systemic glucocorticoids therapy on bone metabolism and the osteoprotegerina system in patients with active Crohn's disease. Eur J Gastroenterol Hepatol 2003; 15: 1165-70.

28. Habtezion A, Silverberg MS, Parkes R, Mikolainis S, Steinhart AH. Risk factors for low bone density in Crohn's disease. Inflamm Bowel Dis 2002; 8: 87-92.

29. de Jong DJ, Corstens FH, Mannaerts L, van Rossum LG, Naber AH. Corticosteroid-induced osteoporosis: does it occur in patients with Crohn's disease? Am J Gastroenterol 2002; 97: 2011-5.

30. Schulte CM, Dignass AU, Goebell H, Roher HD, Schulte KM. Genetic factors determine extent of bone loss in inflammatory bowel disease. Gastroenterology 2000; 119: 909-20.
31. Lichtenstein GR. Evaluation of bone mineral density in inflammatory bowel disease: current safety focus. Am J Gastroenterol 2003; 98: S24-30.

32. Scott EM, Gaywood I, Scott BB. Guidelines for osteoporosis in coeliac disease and inflammatory bowel disease. British Society of Gastroenterology. Gut 2000; 46 (Supl. 1): i1-8.

33. Robinson RJ, Iqbal SJ, Abrams K, Al-Azzawi F, Mayberry JF. Increased bone resorption in patients with Crohn's disease. Aliment Pharmacol Ther 1998; 12: 699-705.

34. Schoon EJ, Muller MC, Vermeer C, Schurgers LJ, Brummer RJ, Stockbrugger RW. Low serum and bone vitamin K status in patients with longstanding Crohn's disease: another pathogenetic factor of osteoporosis in Crohn's disease? Gut 2001; 48: 473-7.

35. Loftus EV, Jr., Achenbach SJ, Sandborn WJ, Tremaine WJ, Oberg $\mathrm{AL}$, Melton LJ, 3rd. Risk of fracture in ulcerative colitis: a population-based study from Olmsted County, Minnesota. Clin Gastroenterol Hepatol 2003; 1: 465-73.

36. Arden NK, Cooper C. Osteoporosis in patients with inflammatory bowel disease. Gut 2002; 50: 9-10.

37. Card T. Hip fractures in patients with inflammatory bowel disease and their relationship to corticosteroid use: a population based study. Gut 2004; 53: 251-5.

38. Loftus EV, Jr, Crowson CS, Sandborn WJ, Tremaine WJ, O'Fallon WM, Melton LJ, 3rd. Long-term fracture risk in patients with Crohn's disease: a population-based study in Olmsted County, Minnesota. Gastroenterology 2002; 123: 468-75.

39. García-Planella E. Osteoporosis y enfermedad inflamatoria intestinal; 2002.

40. Clements D, Motley RJ, Evans WD, Harries AD, Rhodes J, Coles RJ, et al. Longitudinal study of cortical bone loss in patients with inflammatory bowel disease. Scand J Gastroenterol 1992; 27 : 1055-60.

41. Leslie WD. All patients with inflammatory bowel disease should have bone density assessment: con. Inflamm Bowel Dis 2001; 7: 1637; discussion 168-9.

42. Bernstein CN. Extraintestinal manifestations of inflammatory bowel disease. Curr Gastroenterol Rep 2001; 3: 477-83.

43. Compston JE. Can biochemical markers be used to screen patients with inflammatory bowel disease for osteoporosis? Eur J Gastroenterol Hepatol 2002; 14: 587-9.

44. Papaioannou A, Ferko NC, Adachi JD. All patients with inflammatory bowel disease should have bone density assessment: pro. Inflamm Bowel Dis 2001; 7: 158-62; discussion 168-9.

45. Silvennoinen J, Risteli L, Karttunen T, Risteli J. Increased degradation of type I collagen in patients with inflammatory bowel disease. Gut 1996; 38: 223-8

46. Ledro Cano D, Torres Dominguez Y, Castro Laria L, Saenz Dana M, Herrerias Esteban JM, Herrerias Gutierrez JM. Biochemical markers and bone densitometry in inflammatory bowel disease. Rev Esp Enferm Dig 2000; 92: 595-600.

47. Bailen LS. Bones and Crohn's: should we treat Crohn's disease patients with alendronate? Inflamm Bowel Dis 2001; 7: 175-6.

48. Vogelsang H, Ferenci P, Resch H, Kiss A, Gangl A. Prevention of bone mineral loss in patients with Crohn's disease by long-term oral vitamin D supplementation. Eur J Gastroenterol Hepatol 1995; 7: 609-14.

49. von Tirpitz C, Klaus J, Bruckel J, Rieber A, Scholer A, Adler G, et al. Increase of bone mineral density with sodium fluoride in patients with Crohn's disease. Eur J Gastroenterol Hepatol 2000; 12: 19-24.

50. Adachi JD, Bensen WG, Brown J, Hanley D, Hodsman A, Josse R, et al. Intermittent etidronate therapy to prevent corticosteroid-induced osteoporosis. N Engl J Med 1997; 337: 382-7.

51. Haderslev K. Alendronate increases lumbar spine mineral density in patients with Crohn's disease. Gastroenterol 2000; 119: 63946.

52. Bartram SA, Peaston RT, Rawlings DJ, Francis RM, Thompson NP. A randomized controlled trial of calcium with vitamin $\mathrm{D}$, alone or in combination with intravenous pamidronate, for the treatment of low bone mineral density associated with Crohn's disease. Aliment Pharmacol Ther 2003; 18: 1121-7.

53. Danes I. ¿Cómo se puede prevenir y tratar la osteoporosis inducida por glucocorticoides? Med Clin (Barc) 2003; 120: 473-5. 